\title{
Online erotica usage as a mediator between internet addiction and engagement in risky online sexual behaviors
}

\author{
Michelle Drouin \& Daniel A. Miller \\ Indiana University-Purdue University Fort Wayne, Fort Wayne, IN, United States
}

\begin{abstract}
In this study, we examined the links between Internet addiction, engagement in online erotica (including pornography usage and usage of sex-based Internet chat sites), and engagement in risky online sexual behaviors, in this case, sending sexually-explicit pictures to those known only online (i.e., sexting) and expecting to engage in offline sex with those known only online. In our sample of 276 U.S. adults, men engaged in most of these online sexual activities significantly more than women, but women were just as likely as men to send sexually-explicit pictures to online chat partners, and they were also just as likely as men to demonstrate signs of internet addiction. More importantly, using pornography and sex site usage were sequential mediators in the relationship between Internet addiction and engagement in risky online sexual activities. Moreover, whereas pornography viewing alone was not a predictor of risky online sexual activities, when the behavior escalated to engaging in Internet sex chat sites it did predict engagement in sexting or expectations of offline sex with those known only online. Based on these findings, we suggest that although these behaviors might be considered under one umbrella of online sexual activity, it might be useful from an intervention and treatment standpoint to target specific online sexual activities (e.g., sex site usage).
\end{abstract}

Keywords: internet addiction; online erotica; sexting; risky sexual behavior; online sexual behaviors

\section{Introduction}

For almost two decades, researchers have shown empirical interest in the links between Internet activity and risky sexual behavior. In fact, a growing body of research now exists examining the ways in which Internet use and addiction relates to Internet sexuality, which includes a variety of behaviors, such as consumption of pornography, visiting online sex chat rooms, and even meeting online partners for offline sexual contact (e.g., Döring, 2009; Griffiths, 2001; Jones \& Hertlein, 2012; Judge \& Saleh, 2013; Pratarelli \& Browne, 2002; Young, 2008). In a separate body of work, researchers have investigated the associations between sexting (i.e., the transmission of sexual material via technological devices) and risky offline sexual behavior among adults (e.g., Benotsch, Snipes, Martin, \& Bull, 2013; Crimmins \& Seigfried-Spellar, 2014; Dir, Cyders, \& Coskunpinar, 2013; Drouin, 2015; Ferguson, 2011; Gordon-Messer, Bauermeister, Grodzinski, \& Zimmerman, 2013; Klettke, Hallford, \& Mellor, 2014). These studies have produced mixed results, but generally they have found that sexting is related to a variety of offline, risky sexual behaviors, including sex with multiple partners, unprotected sex, and sex while under the influence of alcohol or drugs. In their recent study, Crimmins and Seigfried-Spellar (2014) combined the themes of online sexual activities and sexting and found that using the Internet to engage in webbased chat with strangers and using adult pornography was predictive of sending a seminude or nude photo or 
video via text. In this study, we sought to extend this line of inquiry by examining the extent to which Internet addiction was associated with online sexual activities (in this case, use of pornography and sexual chat sites) and risky sexual behaviors among adults, including the sending of sexually-explicit photos to online-only chat partners and expectations of sex with online-only chat partners.

\section{Internet Addiction}

As the Internet has gained popularity on a global scale, there has been rising concern surrounding Internet addiction, or the pathological use of the Internet characterized by difficulty in controlling usage, which causes problems in the user's life (Young, 1998a). These concerns appear to be well-founded, as a recent meta-analysis by Cheng \& Li (2014) showed that the prevalence rate of Internet addiction across 31 nations was approximately $6 \%$, with the highest rates in the Middle East (11\%) and the lowest rates in Northern and Western Europe (3\%). In North America, where the present study was conducted, the average rate of Internet addiction was 8\% (Cheng \& $\mathrm{Li}$, 2014), and the most recent U.S. statistics show that daily Internet use is common for most (71\%), whereas "almost constant" use is reported among $21 \%$ of Americans (Perrin, 2015).

Since its initial conceptualization, researchers have varied widely in their chosen nomenclature for Internet addiction, using terms such as problematic Internet use, excessive Internet use, and Internet dependency (Pawlikowski, Nader, Burger, Stieger, \& Brand, 2014). There has also been considerable debate as to its definition and diagnosis (Carlisle, Carlisle, Polychronopoulos, Goodman-Scott \& Kirk-Jenkins, 2016; Young, 2015), especially as Internet Addiction is not included in DSM-5 as a diagnosable disorder. Additionally, although most researchers generally agree that Internet addiction is maladaptive and related to uncontrolled or compulsive behavior related to Internet use (e.g., Caplan, 2003; Davis, 2001; Griffiths, 1996; Young, 1998a), there is some debate on whether or not it constitutes an independent construct, especially when it serves as a gateway to other types of addictive behaviors, like Internet gambling, Internet gaming, or sex site addictions (Bőthe, TóthKirály, \& Orosz, 2015; Griffiths, Kuss, Billieux, \& Pontes, 2016; Jones \& Hertlein, 2012; Pawlikowski et al., 2014; Starcevic, 2013; Starcevic \& Aboujaoude, 2015). This has prompted some researchers to propose that Internet addiction is a multi-dimensional construct (Pawlikowski et al., 2014) or that there might be both general and specific Internet addictions (Davis, 2001; Montag et al., 2015).

According to Davis's (2001) cognitive-behavioral model, general pathological Internet use is characterized by a non-localized addiction to the Internet, whereas with specific pathological Internet use, the user engages in specific online behaviors that are problematic, like gaming or gambling. From this perspective, Internet addiction can be parsed out into, may be comorbid with, and may predict other types of addictive Internet behaviors. Meanwhile, other researchers approach Internet addiction as a component of a larger family of addictions (e.g., Billieux, 2012; Carlisle, et al., 2016) which have been classified by some (e.g., Carlisle et al., 2016) as process addictions (or compulsive behaviors and urges that are disruptive to functioning; American Psychiatric Association, 2013). These perspectives are not mutually exclusive, and as we have gathered more empirical evidence on Internet addiction, it is becoming clear that our understanding of the construct is still evolving. However, it has prompted researchers to explore the predictive relationship between general Internet addiction and other types of specific Internet behaviors, like Internet gaming, pornography usage, and engaging with Internet sex chat sites (e.g., Bőthe et al., 2015; Pawlikowski et al., 2014).

\section{Online Sexual Activities}

In her review of Internet sexuality, Döring (2009) delineated six broad areas that comprise Internet sexuality, including "pornography, sex shops, sex work, sexual education, sex contacts, and sexual subcultures" (p. 1089). For more than 20 years, researchers have been conducting studies of users' behaviors and characteristics within these six domains of online sexuality. More specific to the present study, Döring (2009) described pornography as the access or production of pornographic images and sex contacts as contacts with whom one engages online towards the end of either online or offline sex. This is a slightly different classification scheme than that proposed by Cooper, Månsson, Daneback, Tikkanen, and Ross (2003), who identified two types of Internet sex users: Those who engage in Internet sexual behaviors to engage in online erotica, which could include sexual chat with online partners, and those who use the Internet to solicit offline sexual partners. Interestingly, neither of these classification schemes includes specific mention of sexting, or the sending of sexually-explicit pictures 
or videos via Internet or cell phone, which exemplifies the gap that exists between the sexting and online sexual activity literature. For the purpose of the present study, we adapted Döring's (2009) and Cooper et al.'s (2003) classifications, examining pornography and sex site usage as separate online erotica activities and sexting with pictures and expected offline sexual activity with online partners as risky online sexual behaviors.

With regard to online erotica, pornography consumption has been found to be common among both men and women in the U.S. (Shaughnessy, Byers, \& Walsh, 2011; Wright, 2013; Wright, Bae, \& Funk, 2013). In terms of general pornography viewing, $36 \%$ of men and $17 \%$ of women reported watching at least one pornographic movie in 2010, and these prevalence statistics have stayed rather stable across four decades (Wright, 2013; Wright et al., 2013). Meanwhile, with regard to Internet pornography specifically, Shaughnessy et al. (2011) found that $83 \%$ of young adult men and $21 \%$ of young adult women reported solitary viewing of online sexually-explicit videos or photos during the last month. Additionally, compulsive pornography viewing has garnered its own empirical attention as a compulsive disorder (e.g., Cooper, Delmonico, \& Burg, 2000; Griffiths, 2012; Grubbs, Stauner, Exline, Pargament, \& Lindberg, 2015; Grubbs, Volk, Exline, \& Pargament, 2015; Young, 2008). However, this has come under recent scrutiny as there is disagreement about whether this type of online compulsive sexual behavior is distinct from general sex addiction, and there is also debate over how it should be classified and diagnosed (Duffy, Dawson, \& das Nair, 2016; Jones \& Hertlein, 2012). Moreover, many of those who use the Internet for sexual pursuits do not consider their online sexual activities problematic (Cooper, Scherer, Boies, \& Gordon, 1999). For example, only $13 \%$ of men and 5\% of women in Ross, Månsson, and Daneback's (2012) sample of Swedish adults report some sexual problems with Internet sexual addiction, and only $5 \%$ of men and $2 \%$ of women report serious problems with Internet sexual addiction. Internet sex chat usage is also fairly common among adults. Cooper et al. (2003) found that among the three fourths of their adult Swedish sample who answered their question about online sex and love, $37 \%$ of men and $27 \%$ of women had visited contact sex sites. These statistics are slightly higher than those reported by Laier, Pekal, and Brand (2014), who found that $18 \%$ of their sample of heterosexual German women used sex sites. Differences between these statistics may stem from sample characteristics (i.e., those who had engaged in some sort of online sexual activity versus a general sample) or cultural differences.

In terms of risky online sexual behaviors, there is empirical evidence that some people convert these online sexual exchanges into offline sexual experiences. For example, in their Swedish adult sample, Daneback, Månsson, and Ross (2007) found that of those who had used the Internet for sexual purposes, 35\% of women and $40 \%$ of men reported meeting online partners for offline sex. Those who engaged in cybersex were more likely to convert their online chats into offline sexual encounters (Daneback et al. 2007), as were 30-65 year-old women, homo-and bisexual men, and those who were single. Meanwhile, within their U.S. sample of men who have sex with men, Kerr, Pollack, Woods, Blair, and Binson (2015) found that among men who had just visited a bathhouse, $47 \%$ used online sex sites to find offline sex partners within the last three months. Combined, these studies suggest that engagement in online sexual activity might lead to offline sexual encounters, especially for certain subsets of the population. Additionally, a recent study has shown that use of these online erotic platforms may relate to another risky sexual behavior - the sending of sexually-explicit pictures. Crimmins and Seigfriend-Spellar (2014) found that among their U.S. undergraduates, those who viewed Internet pornography were 4 times more likely to have sent send a seminude or nude photo or video of themselves, and those who had engaged in web-based video chatting with online strangers were 2.4 times more likely to have sent a seminude or nude photo or video of themselves.

\section{Current Study}

Recently, researchers have begun to examine the predictive relationships between Internet addiction and other types of online behaviors and addictions, including pornography addiction. For example, Pawlikowski et al. (2014) found that in their German sample of Internet gamers and Internet pornography users, time spent online was predictive of compulsive use in both groups. Meanwhile, Bőthe et al. (2015) examined the predictive relationship between problematic Internet use, gaming, and pornography use in a sample of Hungarian university students. They found that problematic Internet use predicted pornography use, but aspects online gaming addiction also predicted pornography use, even after the effects of general problematic use were controlled for (Böthe et al., 2015). These findings support the idea that general Internet addiction may exist concurrently with and even predict specific online addictions and behaviors. Moreover, Daneback et al. (2007) 
and Crimmins and Seigfriend-Spellar (2014), found that those who engaged in cybersex encounters were more likely to convert their online sexual chats into offline sexual encounters and send sexually-explicit pictures of themselves, respectively, thus providing an empirical link between online erotica and risky online sexual behaviors. In this study, we sought to marry the two lines of inquiry, examining the predictive relationship between Internet addiction, engagement in online erotica, and engagement in risky online sexual behaviors. With consideration for the extant literature, we expected that engagement in online erotica might be a mediator in the relationship between Internet addiction and engagement in risky online sexual behaviors.

Additionally, we wanted to explore whether the prevalence of or relationships between these different online sexual behaviors differed by gender, as some researchers have found gender differences in the prevalence of these behaviors. For example, men show stronger motivations towards Internet pornography consumption than women (Paul \& Shim, 2008; Shaughnessy et al., 2011). Men also report greater engagement than women in "partnered-arousal online sexual activity": 25\% of men versus 15\% of women in Shaughnessy et al.'s (2011) Canadian adult sample had engaged in some sort of partnered-arousal Internet activity. Similarly, Cooper et al. (2003) found that among Swedish adults who had used the Internet for sexual purposes at least once, 37\% of men and $27 \%$ of women had visited contact sex sites. However, they also found that men preferred visual online erotica more than women ( $37 \%$ vs. $6 \%$, respectively), but women preferred online sex chatting with people with similar interests more than men (10\% vs. $17 \%$, respectively). Cooper et al. (2003) suggest that this difference is because women may be using the Internet (even sexual sites) to build relationships, whereas men are searching more for and responding more to visual cues. In support of this idea, Daneback et al. (2007) found that women who used the Internet for sexual purposes were slightly more likely to meet online partners for offline sex (40\% of women vs. $35 \%$ of men reported this behavior), which again emphasizes the idea that women may engage in online sexual activities with the goal of fostering a relationship. That said, in their sample of young adults, heterosexual German women, Laier et al. (2014) found that $51 \%$ of the women were regular Internet pornography users but only $18 \%$ engaged in online sex chats, had sex via webcam and/or used Internet dating sites. Thus, it is unclear whether there are any consistent gender differences in prevalence for these online sexual activities. To address these research questions, we conducted a survey study in the U.S. using Amazon's MTurk.

\section{Methods}

\section{Participants}

Participants ( $N=276$ ) were recruited online through Amazon's MTurk, and we narrowed our selection criteria so that only adults who lived in the United States were eligible to participate. Amazon's MTurk has become increasingly popular for social science research. According to Buhrmester, Kwang, and Gosling (2011), data gathered from MTurk workers shows comparable reliability as that gathered from other, more traditional methods of data collection. More specifically, data gathered multiple scales from MTurk samples have alpha levels in the good to excellent range, and test-retest reliabilities are also acceptable (Buhrmester et al., 2011). Additionally, there is much empirical evidence that MTurk participants perform similarly on various measures (including priming and behavioral tasks, and measures of emotional reactions, personality, and political ideation) to those recruited via other standard recruitment methods, like college samples or through social media (e.g., Casler, Bickel, \& Hackett, 2013; Clifford, Jewell, \& Waggoner, 2016; Eriksson \& Simpson, 2010; Feitosa, Joseph, \& Newman, 2015; Horton, Rand, \& Zeckhauser, 2011). Moreover, MTurk samples have been used specifically to conduct research in the field of sexuality (e.g., Séguin, Milhausen, \& Kukkonen, 2015; Webster \& Crysel, 2012).

From the original sample, four participants were excluded, one for failing an attention check, one for completing the survey in less than five minutes, and two for providing a numerical answer to a sexual experience question that was more than 3 SDs above the mean. Thus, the final sample $(N=272)$ were 141 men and 131 women who reported residence in 41 states across the following U.S. regions: Northeast $=22 \%$, Southeast $=21 \%$, Midwest $=$ $18 \%$, South Central $=18 \%$, and West $=21 \%$. Their average age was 32.22 years $(S D=8.32$, range $=18-69)$ and $75 \%$ identified themselves as White, 9\% African American, 8\% Asian, 5\% Hispanic, and 3\% other. Most (86\%) were heterosexual and $99 \%$ had completed high school, with $85 \%$ reporting at least some college or trade/vocational training. With regard to relationship status, $45 \%$ indicated that they were currently single, 31\% were married, and $24 \%$ were in a committed relationship, but not married. 


\section{Procedure}

Participants were recruited online through Amazon's MTurk for a larger study on online deception experiences. Participants who accepted the online assignment first completed an online consent form and then were given access to an online survey that contained demographic questions, questions about their online and offline sexual behaviors and expectations of sexual behavior with online chat partners, and a measure of Internet addiction (as well as other measures, not reported here). After completing the survey, participants received $\$ 1.50$ USD in their Amazon.com account.

\section{Measures}

Pornography and sex sites usage. Participants were asked to indicate how often they used pornography (i.e., "How often have you accessed online pornography websites (e.g., Pornhub, etc.)" and how often they had visited sexual chat sites (i.e., "How often have you used social media sites, chat rooms, or other web sites aimed at communicating with potential sexting or sexual partners (e.g., Craigslist Casual Encounters, Ashley Madison, or sexual fetish chat rooms)?" Participants answered the pornography and sex chat site frequency questions using a 5-point Likert-type scale $\left(1=\right.$ never, $5=$ always $\left.{ }^{1}\right)$.

Sexting pictures with online-only chat partners. Participants were asked "Approximately how many times have you sent sexually-explicit picture messages to people you have only known online (i.e., you have never met them in person)?" A similar question was used in the Sex and Tech Survey (National Campaign to Prevent Teen and Unplanned Pregnancy, 2008), but in that case, they asked participants whether they had sent sexuallyexplicit material to those known only online. To get a more detailed picture of this behavior, we adapted the Sex and Tech Survey question by asking participants to provide numerical answers and specifying that the content was a sexually-explicit picture. Participants' responses ranged from 0 to 200.

Expectations of sex with online-only chat partners. Participants were asked about their agreement with two statements on sexual expectations related to sexting: "If I send sexually-explicit messages to someone I know only online, we will likely engage in the sexual activities we mention in the chat." and "If I send sexually-explicit messages to someone I know only online, we will likely engage in sexual activity the first time we see each other." Participants responded on a Likert agreement scale ( $1=$ strongly disagree, $5=$ strongly agree). Responses from these two questions were averaged, forming a composite measure (Cronbach's alpha $=.85$ ).

Internet addiction. To measure Internet addiction, we used Young's (1998b) Internet Addiction Test (IAT), which is the first Internet addiction measure to have been validated (Widyanto \& McMurren, 2004) and remains one of the most widely-used measures of Internet addiction today. Participants responded on a 6-point frequency Likert scale $(0=$ does not apply, $5=$ always) to 20 statements (e.g., "How often do you fear that life without the Internet would be boring, empty, and joyless?") about their thoughts, feelings, and behaviors regarding their own Internet use. According to the criteria provided by Young (1998b), a point sum of 20-49 indicates an average internet user, 50-79 points indicates moderate internet addiction, and 80-100 points indicates significant internet addiction. The sums for this sample ranged from $0-100$, with a mean sum of $28.74(M=28.74, S D=16.90)$. According to the criteria, most of the sample (89\%) were average internet users, $11 \%$ were moderately addicted to the internet, and only one person reported significant internet addiction. For ease of interpretation, the mean scores for the Likert scale were used in all analyses $(M=1.44, S D=0.84$, range $=0-5$, Cronbach's alpha $=.95)$.

\section{Results}

Our main research question was whether there were predictive relationships between Internet addiction, engagement in online erotica (i.e., pornography use and use of sex sites), and risky online sexual activities (i.e., sexting and expectations of sex with online-only chat partners). More specifically, we wanted to test whether online erotica use mediated the relationship between Internet addiction and risky online sexual activity. However, first we examined the prevalence of these behaviors among men and women to see if there were gender differences, as well as the correlations between all of these online sexual activities. 
As shown in Table 1, men engaged in online erotica significantly more than women: Men used significantly more pornography than women ( $92 \%$ vs. $60 \%$, respectively, reported accessing online pornography more than never), and they also reported visiting sex chat sites significantly more frequently than women $(40 \% \mathrm{vs} .9 \%$, respectively, reported using Internet sex chat sites more than never). Additionally, men were significantly more likely than women to expect offline sexual encounters stemming from sex chats with those known only online (30\% vs. $13 \%$ agreed to this statement). The only online sexual activity for which men and women did not significantly differ was the sending of sexually-explicit photos to those known only online. Approximately one in five people surveyed had sent sexually-explicit pictures to those known only online, and although men were more likely than women to report having done this ( $26 \%$ vs. $21 \%)$, the difference was not significant. Finally, there were no significant differences between men and women in their Internet addiction scores.

Table 1. Descriptive Statistics for and Differences between Men and Women in Their Use of Online Pornography \& Sex Sites, Sexting Pictures with Online Partners, Expectations of Sex With Online Partners, and Internet Addiction.

\begin{tabular}{lcccccc}
\hline & \multicolumn{2}{c}{ Men } & \multicolumn{2}{c}{ Women } & & \\
\cline { 5 - 8 } & $M(S D)$ & \% Ever/Yes & $M(S D)$ & $\%$ Ever/Yes & $t$ & $d$ \\
\hline Porn freq. & $3.22(1.07)$ & $92 \%$ & $1.98(0.99)$ & $60 \%$ & $9.85^{* * *}$ & 1.20 \\
Sex sites freq. & $1.63(0.90)$ & $40 \%$ & $1.34(0.82)$ & $9 \%$ & $2.72^{* *}$ & 0.34 \\
\# Sex pics online partner & $6.28(18.83)$ & $26 \%$ & $5.52(25.90)$ & $21 \%$ & 0.28 & 0.03 \\
Expect sex online partner & $2.56(1.09)$ & $30 \%$ & $2.00(1.08)$ & $13 \%$ & $4.28^{* * *}$ & 0.52 \\
Internet addiction $^{a}$ & $1.47(0.86)$ & $11 \%$ & $2.40(0.83)$ & $10 \%$ & 0.65 & 0.08 \\
\hline
\end{tabular}

Note: Men $n=138$. Women $n=130 .{ }^{*} p<.05 .{ }^{* \star} p<.01 .{ }^{*} p<.001$. Internet addiction ${ }^{a} \%$ ever/yes $=$ the percentage of people classified as at least having moderate Internet addiction based on their sum scores. For measures of Porn freq., Sex sites freq., and Expect sex online partner, mean range $=1-5$. For \#Sex pics online partner, range $=0-200$. For Internet addiction, mean range $=0-5$.

Next, we examined the zero-order correlations between these variables. Because of the differences in mean scores by gender, we analyzed these relationships separately for men and women. As shown in Table 2, among men, Internet addiction was significantly associated with pornography use, sex site use, and sexting pictures; however, it was not significantly related to expectations of sex with offline chat partners. Additionally, each of these online sexual activities was significantly related to one another, except for pornography usage and expectations of offline sex with online chat partners. Meanwhile, among women, Internet addiction was related to using sex sites and also to expectations of offline sex with online chat partners. Moreover, sex site usage was related to pornography usage, the number of sexually-explicit pictures women sent to those known only online, and expectations of sex with online chat partner. In contrast, pornography usage among women was not related to either sending sexually-explicit pictures or expectations of offline sex with online chat partners.

Table 2. Correlations between Use of Online Pornography \& Sex Sites, Sending Sex Pictures and Expectations of Sex with Online Chat Partners, and Internet Addiction for Men and Women.

\begin{tabular}{llllll}
\hline & $\mathbf{1}$ & $\mathbf{2}$ & $\mathbf{3}$ & $\mathbf{4}$ & $\mathbf{5}$ \\
\hline 1. Porn freq. & -- & $.22^{\star *}$ & $.27^{\star *}$ & -.02 & $.35^{\star *}$ \\
2. Sex sites freq. & $.29^{\star *}$ & -- & $.35^{\star *}$ & $.24^{\star *}$ & $.27^{* *}$ \\
3. \# Sex pictures online partner & .11 & $.34^{\star *}$ & -- & $.25^{\star *}$ & $.36^{\star *}$ \\
4. Expect sex online partner & .04 & $.20^{*}$ & .11 & -- & .14 \\
5. Internet addiction & .16 & $.25^{\star *}$ & .12 & $.19^{*}$ & -- \\
\hline
\end{tabular}

Note: Men's correlations are displayed above the diagonal. Women's correlations are displayed below the diagonal. ${ }^{\star} p<.05$. $* * p<.01$.

Finally, to explore the predictive relationships between Internet addiction, pornography usage, sex site usage, and risky sexual behaviors, we submitted participants' responses to a path analysis using PROCESS (Hayes, 2013). Two separate models were created, one for each of the risky sexual behaviors we examined: Expectations of sex with online-only chat partners (see Figure 1), and sexting pictures with online-only partners (see Figure 2). For both of these models, pornography usage and sex site usage were entered as sequential mediators in the relationship between Internet addiction and risky sexual behavior. Although there was a gender difference in 
some of the correlations between these online sexual behaviors, gender did not moderate any of the relationships shown in Figures 1 or 2; thus, it was not included in the final models.

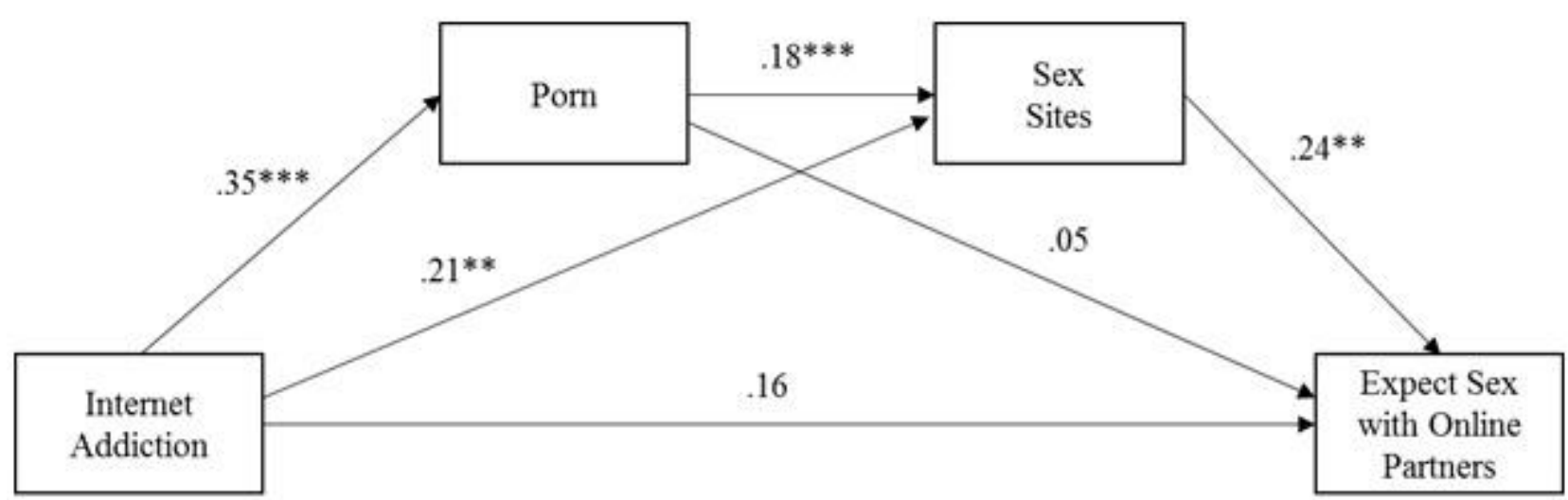

Figure 1. Regression model for expecting offline sex with sex chat partners known only online. Regression coefficients are non-standardized. ${ }^{*} p<.05,{ }^{* *} p<.01,{ }^{* \star} p<.001$.

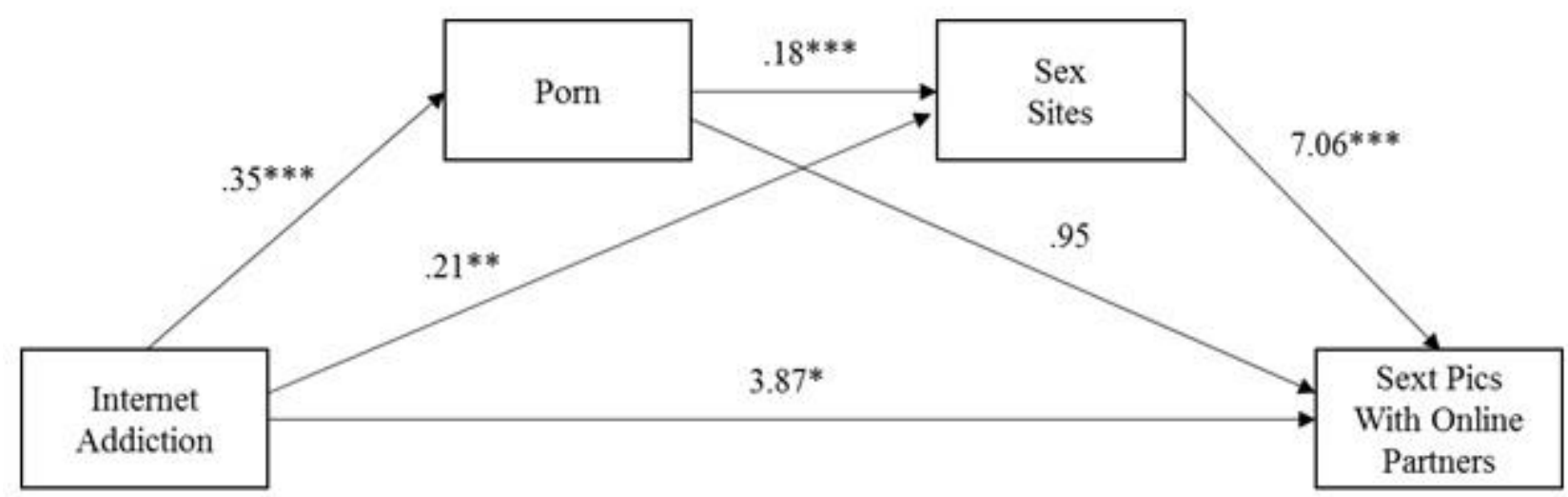

Figure 2. Regression model for sending sexually-explicit pictures to those known only online. Regression coefficients are non-standardized. ${ }^{*} p<.05, * \star p<.01, * \star \star x p .001$.

Direct effects. Both models displayed similar patterns of direct effects (see Figures 1 \& 2). In both models, Internet addiction was significantly related to both pornography usage and sex site usage. Furthermore, in both models, increased pornography use was associated with increased sex site usage. Sex site usage had a significant direct relationship with both sending sexually-explicit pictures to online-only chat partners and expectations of sex with online-only chat partners. However, for pornography usage, there were no significant direct relationships with either sending sexually-explicit pictures or expectations of sex with online-only chat partners. The only difference between the two models centered on the direct effect of Internet addiction: With respect to sending sexually-explicit pictures, there was a significant direct effect of Internet addiction, however, there was no direct effect of Internet addition on expectations of sex with online-only chat partners.

Indirect effects. Again both models had similar patterns of indirect effects (see Table 3). The indirect effect of Internet addiction to risky sexual behavior through pornography alone was not significant in either model. However, the indirect effect of Internet addiction to risky sexual behavior through sex site usage alone was significant. Moreover, the indirect effect of Internet addiction to risky sexual behavior through both pornography use and sex site use was significant for both models. 
Table 3. Direct and Indirect Effects for Internet Addiction, Engagement in Online Erotica, and Engagement in Risky Online Sexual Behaviors.

\begin{tabular}{lllll}
\hline & $\boldsymbol{b}$ & SE & $\mathbf{9 5 \% ~ L L C l}$ & $\mathbf{9 5 \%}$ ULCI \\
\hline Expect Sex with Online Partners & & & & \\
$\quad$ Internet addiction $\rightarrow$ Porn & .0185 & .0222 & -.0173 & .0786 \\
$\quad$ Internet addiction $\rightarrow$ Porn $\rightarrow$ Sex Sites & $\mathbf{. 0 1 5 4}$ & .0083 & .0034 & .0370 \\
$\quad$ Internet addiction $\rightarrow$ Sex Sites & $\mathbf{. 0 5 3 0}$ & .0260 & .0119 & .1202 \\
Sext Pictures with Online Partners & & & & \\
$\quad$ Internet addiction $\rightarrow$ Porn & .3317 & .3927 & -.3328 & 1.2527 \\
$\quad$ Internet addiction $\rightarrow$ Porn $\rightarrow$ Sex Sites & $\mathbf{. 4 4 4 1}$ & .2510 & .1276 & 1.2549 \\
$\quad$ Internet addiction $\rightarrow$ Sex Sites & $\mathbf{1 . 5 3 2 6}$ & .9995 & .3332 & 4.7686 \\
\hline
\end{tabular}

Note: Coefficients in bold are significant at the $p<.05$ level

\section{Discussion}

Our primary research question was whether there was a predictive relationship between Internet addiction and risky online sexual behaviors, specifically, sending sexually-explicit pictures to those known only online and expecting offline sex with online-only chat partners, and whether this relationship was mediated by use of online erotica (in this case, pornography viewing and using Internet sex chat sites). However, before we conducted these analyses, we first examined the prevalence of these online sexual behaviors in our U.S. sample as well as gender differences in these behaviors.

Overall, our prevalence statistics for these online sexual activities are slightly different (some lower, some higher) than what has been found in other studies conducted in different countries. For example, in our sample, $92 \%$ of men and $60 \%$ of women reported that they had ever used pornography. These statistics are higher than those reported by Shaughnessy et al. (2011) who found that $83 \%$ of young adult men and $21 \%$ of young adult women in their Canadian sample had used pornography in the last month. The statistics for women are also higher than those reported by Laier et al. (2014), where 51\% of their German heterosexual woman sample reported to be regular Internet pornography users. With regard to sex site usage, $40 \%$ of men and $9 \%$ of women in our sample reported ever using sex chat sites. These statistics differ from the $37 \%$ of men and $27 \%$ of women who reported having visited contact sex sites in Cooper et al.'s (2003) Swedish study, and they also differ from the $25 \%$ of men and $15 \%$ of women in Shaughnessy et al.'s (2011) Canadian study who stated that they had engaged in partnered-arousal online sexual activity. Additionally, our prevalence statistics for women are lower than that reported by Laier et al. (2014), who found that $18 \%$ of their sample of heterosexual German women used sex sites. With regard to comparative statistics for the risky online sexual behaviors, no known direct comparisons exist; however, some meaningful contrasts can be made. For instance, in our sample, 30\% of men and $13 \%$ of women expected offline sex with online chat partners, which is much lower than the $35 \%$ of women and $40 \%$ of men who reported meeting online partners for offline sex in Daneback et al.'s (2007) Swedish sample of people who had used the internet for sexual purposes. Meanwhile, $26 \%$ of men and $21 \%$ of women in our sample had sent sexually-explicit pictures to those known only online. These statistics are only slightly higher than the $23 \%$ of young adult men and $15 \%$ of young adult women who reported sending sexually-suggestive material to someone they knew only online in the Sex and Tech Survey (National Campaign to Prevent Teen and Unplanned Pregnancy, 2008)

These disparate findings for online sexual behaviors prevalence rates in our sample as compared to other samples may be attributable to increases in the availability of websites for online sexual activity that have occurred in the last few years, differences in cultural attitudes or beliefs surrounding online sexual activities, or, most likely, differences in how engagement in these online sexual activities was measured (e.g., ever used pornography vs. used in the last month vs. regularly used). Moving forward, it would be useful to conduct a cross-cultural study on online sexual activities to see whether, when measured at the same time point with the same qualifiers, there are any cross-cultural differences in engagement in these online sexual activities. 
Despite these differences in overall prevalence statistics, gender differences were consistent in our sample and, for the most part, they align with the previous literature (Cooper et al., 2003; Daneback et al., 2007; Shaughnessy et al., 2011). Stated simply, men were significantly more likely than women to engage in all of these online sexual activities, with the exception of sending sexually-explicit pictures to those known only online, where men reported engaging in this behavior more often, but not significantly more often, than women. These findings are in contrast to Cooper et al. (2003), who suggested that women prefer chatting with online sex partners (especially chatting with those with similar interests) more than men do. However, they support the idea that men and women may have different uses and gratifications related to their engagement in online sexual activities (Cooper et al., 2003; Daneback et al., 2007; Shaughnessy et al., 2011).

In terms of correlational analyses, there were significant relationships between internet addiction, online erotica use, and online risky sexual behaviors, and this was especially true for men. Meanwhile, for women, sex site usage was strongly associated with each of the other online sexual activities; however, pornography usage was not-it was only significantly related to sex site usage. This suggests that pornography usage may not play as prominent a role for women in predicting their engagement in other online sexual activities. That said, gender was not a significant moderator in these pathways for our predictive models. This suggests that although there are differences in the relationships between online sexual activities for men and women, particularly for pornography usage, the strength of these differences is not strong enough for gender to moderate the relationships in our path models.

Finally, with regard to our main research question-the predictive relationships between these online sexual activity variables-we found support for our predictions. In our models, we found that pornography usage and sex chat site usage were sequential mediators in the relationship between Internet addiction and engagement in risky online sexual behaviors. Moreover, for both types of risky sexual behavior, increased pornography use, which accompanies Internet addiction, was not enough to propel people into risky sexual behavior. Increased pornography use must also progress into increased usage of sex sites in order to lead to risky online sexual behavior. This suggests that for many, there may be a fundamental distinction between passive online sex consumption (e.g., pornography usage) and active online sex seeking (e.g., pursuing online or offline sexual activities with online partners). These activities differ on several critical dimensions, such as level of risk, social acceptability, anonymity, involvement, and goal (i.e., sexual activity with self vs. sexual activity with other). Thus, it is somewhat unsurprising, considering the different affordances of these online venues, that for those whose behavior escalates to the more active online sex seeking also engage in more risky online and offline sexual behavior. Finally, there was a direct effect of Internet addition on sending sexually-explicit pictures to those known only online, which indicates that there may be other factors not related to pornography or sex site usage which may drive Internet addicts to send sexually-explicit pictures to those known only online.

\section{Limitations and Conclusion}

Some aspects of this study limit our interpretation of its findings and its generalizability. First, the measures we used for pornography and sex site usage were basic frequency measures instead of validated scales. It would be helpful, in future, to explore whether internet addiction leads to compulsive use of pornography or sex sites (using validated measures for compulsivity), and whether these compulsive behaviors are also predictive of risky online sexual behaviors. Second, we included only MTurk participants, who although shown to be similar to other samples in measures of behavior and personality (e.g., Casler et al., 2013; Clifford et al., 2016; Eriksson \& Simpson, 2010; Feitosa et al., 2015; Horton et al., 2011) may be different from college samples or those recruited via other methods. Additionally, we included only U.S. residents, who may be different from those residing in other nations, especially in terms of the prevalence of online sexual behaviors. Although there is nothing in our data that would suggest that the predictive relationships between our online sexuality measures would differ across cultures, we look to future, cross-cultural studies to corroborate our findings. Finally, we did not measure or control for personality characteristics, such as impression management/social desirability, impulsivity, or sexual sensation seeking, that might affect engagement in risky behaviors and/or reporting of these behaviors. Our study was focused rather narrowly on online erotica behaviors rather than traits that underlie these behaviors; thus, this is a direction for future research. 
Despite these limitations, overall, these findings suggest that internet addiction is related to online sexual behaviors among both men and women, but the escalation to risky sexual behavior in terms of offline sex and sexting pictures with online-only partners is dependent upon both pornography viewing and engaging with sex chat sites. Moreover, it seems that pornography use alone is not enough to propel internet addicts into engaging in risky online sexual behaviors; instead, users seem to progress in a sequential order from internet addiction to pornography viewing to using online sex chat sites to engaging in these risky sexual behaviors. Thus, rather than considering these online erotica and risky sexual behaviors together under a single umbrella of online sexual activity, it seems useful, from an intervention and treatment standpoint, to address these online sexual activities separately.

\section{Note}

1. "Always" was selected as the ceiling scale point to allow for the possibility that some people may always leave these browsers open, an option selected by $6 \%$ of the sample for the pornography question and $1 \%$ of the sample for the sex site question.

\section{References}

American Psychiatric Association. (2013). Diagnostic and statistical manual of mental disorders (5th ed.). Washington, DC: Author.

Benotsch, E. G., Snipes, D. J., Martin, A. M., \& Bull, S. S. (2013). Sexting, substance use, and sexual risk behavior in young adults. Journal of Adolescent Health, 52, 307-313.

Billieux, J. (2012). Problematic mobile phone use: A literature review and a pathways model. Current Psychiatry Reviews, 8, 299-307.

Bőthe, B., Tóth-Király, I., \& Orosz, G. (2015). Clarifying the links among online gaming, Internet use, drinking motives, and online pornography use. Games for Health, 4, 107-112. http://dx.doi.org/10.1089/g4h.2014.0054

Buhrmester, M., Kwang, T., \& Gosling, S. D. (2011). Amazon's Mechanical Turk: A new source of inexpensive, yet high-quality, data? Perspectives on Psychological Science, 6, 3-5. http://dx.doi.org/10.1177/1745691610393980

Caplan, S. E. (2003). Preference for online social interaction: A theory of problematic Internet use and psychosocial well-being. Communication Research, 30, 625-648.

Carlisle, K. L., Carlisle, R. M., Polychronopoulos, G. B., Goodman-Scott, E., \& Kirk-Jenkins, A. (2016). Exploring Internet addiction as a process addiction. Journal of Mental Health Counseling, 38, 170-182.

http://dx.doi.org/10.17744/mehc.38.2.07

Casler, K., Bickel, L., \& Hackett, E. (2013). Separate but equal? A comparison of participants and data gathered via Amazon's MTurk, social media, and face-to-face behavioral testing. Computers in Human Behavior, 29, 2156-2160. http://dx.doi.org/10.1016/j.chb.2013.05.009

Cheng, C., \& Li, A. Y. (2014). Internet addiction prevalence and quality of (real) life: A meta-analysis of 31 nations across seven world regions. Cyberpsychology, Behavior \& Social Networking, 17, 755-760.

http://dx.doi.org/10.1089/cyber.2014.0317

Clifford, S., Jewell, R. M., \& Waggoner, P. D. (2016). Are samples drawn from Mechanical Turk valid for research on political ideology? Research \& Politics, 2(4), 1-9. http://dx.doi.org/10.1177/2053168015622072

Cooper, A., Delmonico, D. L., \& Burg, R. (2000). Cybersex users, abusers, and compulsives: New findings and implications. Sexual Addiction \& Compulsivity, 7, 5-29. 
Cooper, A., Månsson, S., Daneback, K., Tikkanen, R., \& Ross, M. W. (2003). Predicting the future of Internet sex: Online sexual activities in Sweden. Sexual \& Relationship Therapy, 18, 277.

Cooper, A., Scherer, C. R., Boies, S. C., \& Gordon, B. L. (1999). Sexuality on the Internet: From sexual exploration to pathological expression. Professional Psychology: Research and Practice, 30, 154-164.

http://dx.doi.org/10.1037/0735-7028.30.2.154

Crimmins, D. M., \& Seigfried-Spellar, K. C. (2014). Peer attachment, sexual experiences, and risky online behaviors as predictors of sexting behaviors among undergraduate students. Computers in Human Behavior, 32, 268-275. http://dx.doi.org/10.1016/j.chb.2013.12.012

Daneback, K., Månsson, S., \& Ross, M. (2007). Using the Internet to find offline sex partners. CyberPsychology \& Behavior, 10, 100-107. http://dx.doi.org/10.1089/cpb.2006.9986

Davis, R. A. (2001). A cognitive-behavioral model of pathological Internet use. Computers in Human Behavior, 17, 187-195.

Dir, A. L., Cyders, M. A., \& Coskunpinar, A. (2013). From the bar to the bed via mobile phone: A first test of the role of problematic alcohol use, sexting, and impulsivity-related traits in sexual hookups. Computers in Human Behavior, 29, 1664-1670.

Döring, N. M. (2009). The Internet's impact on sexuality: A critical review of 15 years of research. Computers in Human Behavior, 25, 1089-1101. http://dx.doi.org/10.1016/j.chb.2009.04.003

Drouin, M. (2015). Sexual communication in the digital age. In L. D. Rosen, N. Cheever, \& L. M., Carrier (Eds.), The Wiley handbook of psychology, technology, and society (pp. 176-191). New York, NY: Wiley Blackwell.

Duffy, A., Dawson, D. L., \& das Nair, R. (2016). Pornography addiction in adults: A systematic review of definitions and reported impact. Journal of Sexual Medicine, 13, 760-777. http://dx.doi.org/10.1016/j.jsxm.2016.03.002

Eriksson, K., \& Simpson, B. (2010). Emotional reactions to losing explain gender differences in entering a risky lottery. Judgment and Decision Making, 5, 159-163.

Feitosa, J., Joseph, D. L., \& Newman, D. A. (2015). Crowdsourcing and personality measurement equivalence: A warning about countries whose primary language is not English. Personality \& Individual Differences, 75, 47-ح52. http://dx.doi.org/10.1016/j.paid.2014.11.017

Ferguson, C. J. (2011). Sexting behaviors among young Hispanic women: Incidence and association with other high-risk sexual behaviors. Psychiatric Quarterly, 82, 239-243.

Gordon-Messer, D., Bauermeister, J., Grodzinski, A., \& Zimmerman, M. (2013). Sexting among young adults. Journal of Adolescent Health, 52, 301-306.

Griffiths, M. D. (1996). Internet addiction: An issue for clinical psychology? Clinical Psychology Forum, 97, 32-36.

Griffiths, M. D. (2001). Sex on the Internet: Observations and implications for internet sex addiction. The Journal of Sex Research, 38, 333-342.

Griffiths, M. D. (2012). Internet sex addiction: A review of empirical research. Addiction Research \& Theory, 20, 111 ᄀ-124. http://dx.doi.org/10.3109/16066359.2011.588351

Griffiths, M. D., Kuss, D. J., Billieux, J., \& Pontes, H. M. (2016). The evolution of Internet addiction: A global perspective. Addictive Behaviors, 53, 193-195. http://dx.doi.org/10.1016/j.addbeh.2015.11.001 
Grubbs, J. B., Stauner, N., Exline, J. J., Pargament, K. I., \& Lindberg, M. J. (2015). Perceived addiction to Internet pornography and psychological distress: Examining relationships concurrently and over time. Psychology of Addictive Behaviors, 29, 1056-1067. http://dx.doi.org/10.1037/adb0000114

Grubbs, J. B., Volk, F., Exline, J. J., \& Pargament, K. I. (2015). Internet pornography use: Perceived addiction, psychological distress, and the validation of a brief measure. Journal of Sex \& Marital Therapy, 41, 83-106.

http://dx.doi.org/10.1080/0092623X.2013.842192

Hayes, A. F. (2013). Introduction to mediation, moderation, and conditional process analysis. New York: The Guilford Press.

Horton, J. J., Rand, D. G., \& Zeckhauser, R. J. (2011). The online laboratory: Conducting experiments in a real labor market. Experimental Economics, 14, 399-425. http://dx.doi.org/10.1007/s10683-011-9273-9

Jones, K. E., \& Hertlein, K. M. (2012). Four key dimensions for distinguishing Internet infidelity from internet and sex addiction: Concepts and clinical application. American Journal of Family Therapy, 40, 115-125.

http://dx.doi.org/10.1080/01926187.2011.600677

Judge, A. M., Saleh, F. M. (2013). Sexting, cybersex and Internet use: The relationship between adolescent sexual behavior and electronic technologies. In R. Rosner (Ed.), Clinical handbook of adolescent addiction (pp. 377-389). New York: Wiley.

Kerr, Z. Y., Pollack, L. M., Woods, W. J., Blair, J., \& Binson, D. (2015). Use of multiple sex venues and prevalence of HIV risk behavior: Identifying high-risk men who have sex with men. Archives of Sexual Behavior, 44, 443-451. http://dx.doi.org/10.1007/s10508-014-0352-9

Klettke, B., Hallford, D. J., \& Mellor, D. J. (2014). Sexting prevalence and correlates: A systematic literature review. Clinical Psychology Review, 34, 44-53. http://dx.doi.org/10.1016/j.cpr.2013.10.007

Laier, C., Pekal, J., \& Brand, M. (2014). Cybersex addiction in heterosexual female users of Internet pornography can be explained by gratification hypothesis. Cyberpsychology, Behavior \& Social Networking, 17, 505-511. http://dx.doi.org/10.1089/cyber.2013.0396

Montag, C., Bey, K., Sha, P., Li, M., Chen, Y. F., Liu, W. Y., .. Keiper, J. (2015). Is it meaningful to distinguish between generalized and specific Internet addiction? Evidence from a cross-cultural study from Germany, Sweden, Taiwan and China. Asia Pacific Psychiatry, 7, 20-26. http://dx.doi.org/10.1111/appy.12122

National Campaign to Prevent Teen and Unplanned Pregnancy (2008, December). Sex and tech: Results from a survey of teens and young adults. Retrieved from http://thenationalcampaign.org/resource/sex-and-tech

Paul, B., \& Shim, J. W. (2008). Gender, sexual affect, and motivations for Internet pornography use. International Journal of Sexual Health, 20, 187-199. http://dx.doi.org/10.1080/19317610802240154

Pawlikowski, M., Nader, I. W., Burger, C., Stieger, S., \& Brand, M. (2014). Pathological Internet use - It is a multidimensional and not a unidimensional construct. Addiction Research \& Theory, 22, 166-175.

http://dx.doi.org/10.3109/16066359.2013.793313

Perrin, A. (2015, December 8). One-fifth of Americans report going online 'almost constantly.' Pew Research Center. Retrieved from http://www.pewresearch.org/fact-tank/2015/12/08/one-fifth-of-americans-report-goingonline-almost-constantly/

Pratarelli, M. E., \& Browne, B. L. (2002). Confirmatory factor analysis of Internet use and addiction. CyberPsychology and Behavior, 5, 53-64. http://dx.doi.org/10.1089/109493102753685881 
Ross, M., Månsson, S., \& Daneback, K. (2012). Prevalence, severity, and correlates of problematic sexual Internet use in Swedish men and women. Archives of Sexual Behavior, 41, 459-466. http://dx.doi.org/10.1007/s10508-0119762-0

Séguin, L. J., Milhausen, R. R., \& Kukkonen, T. (2015). The development and validation of the motives for feigning orgasms scale. Canadian Journal of Human Sexuality, 24, 31-48. http://dx.doi.org/10.3138/cjhs.2613

Shaughnessy, K., Byers, E. S., \& Walsh, L. (2011). Online sexual activity experience of heterosexual students: Gender similarities and differences. Archives of Sexual Behavior, 40, 419-427. http://dx.doi.org/10.1007/s10508010-9629-9

Starcevic, V. (2013). Is Internet addiction a useful concept? Australian and New Zealand Journal of Psychiatry, 47, 16-19.

Starcevic, V., \& Aboujaoude, E. (2015). Cyberchondria, cyberbullying, cybersuicide, cybersex: "New" psychopathologies for the 21st century. World Psychiatry, 14, 97-100.

Webster, G. D., \& Crysel, L. C. (2012). "Hit me, maybe, one more time": Brief measures of impulsivity and sensation seeking and their prediction of blackjack bets and sexual promiscuity. Journal of Research in Personality, 46, 591-598. http://dx.doi.org/10.1016/j.jrp.2012.07.001

Widyanto, L., \& McMurran, M. (2004). The psychometric properties of the Internet Addiction Test. CyberPsychology \& Behavior, 7, 443-450. http://dx.doi.org/10.1089/cpb.2004.7.443

Wright, P. J. (2013). U.S. males and pornography, 1973-2010: Consumption, predictors, correlates. Journal of Sex Research, 50, 60-71. http://dx.doi.org/10.1080/00224499.2011.628132

Wright, P. J., Bae, S., \& Funk, M. (2013). United States women and pornography through four decades: Exposure, attitudes, behaviors, individual differences. Archives of Sexual Behavior, 42, 1131-1144.

http://dx.doi.org/10.1007/s10508-013-0116-y

Young, K. S. (1998a). Internet addiction: The emergence of a new clinical disorder. CyberPsychology \& Behavior, 1, 237-244. http://dx.doi.org/10.1089/cpb.1998.1.237

Young K. S. (1998b). Caught in the net. New York: John Wiley.

Young, K. S. (2008). Internet sex addiction risk factors, stages of development, and treatment. American Behavioral Scientist, 52, 21-37. http://dx.doi.org/10.1177/0002764208321339

Young, K. (2015). The evolution of Internet addiction disorder. In C. Montag \& M. Reuter (Eds.), Internet addiction: Neuroscientific approaches and therapeutical interventions (pp. 3-17). New York, NY, US: Springer Science + Business Media.

\section{Correspondence to:}

Michelle Drouin

Department of Psychology

2101 E. Coliseum Blvd.

Fort Wayne, IN, 46805

United States

Email: drouinm(at)ipfw.edu 


\section{About authors}

Michelle Drouin, PH.D. is a Professor of Psychology at Indiana University- Purdue University, Fort Wayne. Her primary research examines innovations in technology, such as texting and social networking, and the effects of these innovations on communication, relationships, sexuality, and human development.

Daniel A. Miller, PH.D. is an Associate Professor in the Department of Psychology at Indiana University Purdue University, Fort Wayne. His main research interests lie in the area of stereotyping and prejudice and social cognition. In particular, the emotional aspects of collective actions in response to social injustice. 